\title{
PINTURA COLONIAL ANDINA: ESTRUCTURA SIMBÓLICA Y SINCRETISMO
}

\author{
COLONIAL ANDEAN PAINTING: SYMBOLIC \\ STRUCTURE AND SINCRETISM
}

\section{FERNANDO A. VALENZUELA*}

\section{RESUMEN}

La pintura andina, como forma característica del arte colonial en los Andes centrales, constituyó un caso de arte primariamente simbólico. En los contornos de la forma de símbolos hierofánticos operaba un medio en el cual la exploración de la estructura fundamental del sentido por medio de la operación de ornamentación se ponía al servicio de la observación de la dimensión trascendente de la realidad. A modo de una estructura de comunicación intercultural, esta forma de organización de la comunicación por medio de imágenes hizo posible que se dieran sincretismos iconográficos y estilísticos, los cuales han sido el principal objeto de interés de la historia social de la pintura andina.

Palabras clave: Arte y sociedad, arte andino, arte colonial, sistemas sociales, teoría de sistemas.

\section{ABSTRACT}

Andean painting, as a characteristic form of colonial art in the central Andes, constituted an art that was primarily symbolic. Surrounding hierophantic symbols, a medium for the reproduction of the operation of ornamentation was made available in which the exploration of the fundamental structure of the medium of meaning was put at the service of the observation of the transcendental dimension of reality. As a structure of

* Dr. Phil. en Sociología. Universidad Andres Bello. Facultad de Humanidades y Ciencias Sociales. Escuela de Sociología. Viña del Mar, Chile. Correo electrónico: fernando.valenzuela@unab.cl 
intercultural communication, this mode of organization of communication through images made possible the occurrence of processes of iconographic and stylistic syncretism, which have been the main object of interest in the social history of colonial Andean painting.

Keywords: Art \& society, Art, Andean, Art, colonial, social systems, Systems Theory.

Recibido: 13.02.12. Aceptado: 12.11.15.

$\mathrm{D}$

OS TEORÍAS, QUE han logrado establecerse como lugares comunes en la disciplina de la historia del arte y en las comunicaciones periféricas de ésta en manuales y catálogos, dan cuenta de la emergencia de la pintura andina, entendida como forma característica del arte pictórico colonial en los Andes centrales, en términos de un sincretismo que ocurriera ya sea en el nivel iconográfico o en el nivel formal-estilístico de las obras (Valenzuela, 2010, 2012, 2013a). Ambas teorías se encuentran representadas en la obra de Teresa Gisbert, especialmente en sus escritos de la década de 1980 (Gisbert, 1980; Mesa y Gisbert, 1982), aunque echan raíces en las primeras décadas del siglo veinte (Cossío del Pomar, 1922, 1928; Picón Salas, 1931) y aún cobran nuevos adherentes.

Al mismo tiempo que los arquitectos bolivianos Teresa Gisbert y José de Mesa estaban inmersos en tales programas de investigación, el sociólogo chileno Pedro Morandé propuso que una síntesis colonial latinoamericana, es decir un sustrato cultural común a esta región, fue posibilitada por la existencia de un punto de encuentro entre las culturas amerindias y la cultura de los hispanos (Morandé, 1987). Tal punto de encuentro no habría tenido lugar en el nivel del discurso reflexivo (es más, Pedro Morandé proponía que en este nivel del discurso se habría desarrollado el conflicto colonial), sino que habría tenido lugar en el nivel ritual, pre-discursivo del sacrificio. En el barroco de la contrarreforma católica, de igual manera a como ocurría en las culturas amerindias, el orden social obtenía legitimación por referencia a valores que eran representados y reactualizados públicamente, especialmente en ocasiones festivas; es decir que eran reactualizados a través de un sacrificio que era asumido por la comunidad como un todo. Así, en estas culturas, el trabajo no era comprendido ni legitimado en términos de una mercancía sino en los de un tributo (Macera, 1977; Morandé, 1987, p. 183).

Este planteamiento de Pedro Morandé, que pretendía volver a poner la 
cultura y los valores en el centro de atención de las investigaciones sobre la evolución social en nuestra región, tenía repercusiones directas para el estudio sociológico del arte. Por una parte porque el arte tenía un lugar central en las fiestas coloniales. Por otra parte porque a través de él-especialmente de la literatura y el teatro- podría observarse de manera privilegiada la síntesis cultural latinoamericana, aún más allá del período colonial. Pero, salvo el importante trabajo de Isabel Cruz de Amenábar (1986) y de María de la Luz Hurtado (1997), y algunas observaciones de Carlos Cousiño sobre la centralidad de la pintura y de la fiesta por sobre el discurso reflexivo, pocos autores siguieron esta línea en el estudio del arte.

Las ya clásicas teorías históricas que fueran desarrolladas por Teresa Gisbert y José de Mesa, las cuales dan sentido a lo que llamaran "Pintura Andina" y, más concretamente, a la Escuela Cusqueña de Pintura, en términos del resultado de procesos de sincretismo iconográfico y formal, no pretenden dar cuenta directamente de lo que Pedro Morandé observó como una estructura de comunicación intercultural. Sin embargo -y esta será la tesis central del presente artículo-, tales procesos de sincretismo presuponen tal estructura de comunicación o punto de encuentro entre culturas (Secciones II y III), a la vez que su estudio permite comprender cómo ésta operara en el dominio de la pintura. Esto requiere acercarnos a lo que era el corazón de la tesis de Pedro Morandé, aunque desde una sociología de las formas de observación anclada en la teoría de Niklas Luhmann (Sección IV).

\section{II}

Una primera teoría adoptada y desarrollada ampliamente por Teresa Gisbert en torno a 1980 señala que se habría producido un proceso de sincretismo en el nivel iconográfico de las pinturas. Más precisamente, las tradiciones amerindias habrían influido en este nivel de la pintura colonial en dos sentidos. De una parte, documentos coloniales sugieren que algunas innovaciones iconográficas pueden haber respondido a las expectativas que los patrones o los clientes tenían sobre las representaciones religiosas de comunidades andinas. De otra parte, ha parecido razonable pensar que algunas representaciones religiosas fueron introducidas por los artistas indígenas, de modo que ellas responderían a las tradiciones religiosas locales. Mientras que en el primer caso las variaciones iconográficas son comprendidas como producto de una propaganda eclesiástica, es decir como parte de una estrategia explícita de evangelización en el cristianismo, en el 
segundo caso ellas son comúnmente comprendidas como el resultado de procesos de sincretismo cultural.

En teoría, ambos fenómenos podían causarse mutuamente. Procesos de sincretismo cultural podían resultar del interés que tenían los sacerdotes por contextualizar, al interior de la tradición cristiana, aquellos símbolos andinos que ellos creían que no estaban directamente relacionados con creencias heréticas. A su vez, artistas nativos pueden haber introducido variaciones iconográficas al utilizar símbolos propios que, aun cuando no eran, según las autoridades cristianas, evidentemente heréticas, cobraban pleno sentido en el contexto de tradiciones religiosas locales, es decir, en el contexto de modos andinos de establecer contacto con lo numinoso (Lara, 1999).

Carácterístico de este contexto cultural es que se generen conductas que son inequívocas en su carácter sacrificial, simbólico o hierofántico en el sentido de Mircea Eliade (Eliade, 1996, p. 448; Rennie, 1996), en el sentido de que ambas partes comprenden inequívocamente que las acciones que están siendo llevadas a cabo tienen un valor sacrificial pues encuentran paralelismos en sus propias tradiciones. Pero si bien tales conductas son inequívocas en su carácter sacrificial, no lo son en su valor al interior de tradiciones discursivas; es decir, en sus respectivas teologías. En este sentido, eran ambiguas en tanto que el sentido o el valor informativo de los comportamientos era distinto dependiendo del contexto teológico en el cual se llevara a cabo y, además, siempre podía ser negado: siempre se podía decir que no se quiso decir lo que el observador comprendió. En términos de Julia Kristeva (1979, p. 35), el símbolo comunicaba en su dimensión vertical, paradójica (distinción inmanente/trascendente), pero no en su dimensión horizontal, desparadojizadora (distinción entre símbolos) ${ }^{1}$.

Esto es lo que apreciamos en el siglo diecisiete, cuando la sola sospecha de que símbolos prehispánicos sobrevivían en contextos de cristianización gatilló feroces campañas contra la idolatría (Duviols, 1972, 1977, 1986, 2003). Ellas, sin embargo, estaban destinadas a fracasar: después de todo, una sospecha de este tipo nunca podía -ni aún puede- ser excluida del todo. Como se observa en el conflicto que ocurriera en 1619 entre un kuraka y un cura local (Spalding, 2002), si bien uno no podía negar el carácter ritual de las propias conductas, su sentido en el marco de tradiciones

${ }^{1} \mathrm{Al}$ respecto, ver también Esposito (1999). 
específicas podía ser negado, alegando un apego estricto a la ritualidad de la religión oficial.

En referencia a las improbabilidades de la comunicación que distinguiera Niklas Luhmann (2007), estamos claramente frente a un problema de comprensión, debido a un contexto de diversidad cultural que sobrepasa el nivel de generalización de los símbolos religiosos: es decir, sobrepasa su capacidad para mantener un sentido estable ante variaciones contextuales. Sin embargo, ante tal improbabilidad de la comunicación, la organización simbólica de los comportamientos y su operación en base a la distinción entre una dimensión inmanente y una trascendente del mundo parece haber sido inescapable para los observadores. Aún más, y en esto radica la tesis de Pedro Morandé: tal organización simbólica no sólo era inescapable, sino que era además experimentada como legítima; ella constituía un modo eficaz de comunicación con la dimensión trascendente de la realidad.

Este contexto sigue determinando la comunicación que se actualiza por medio de las pinturas andinas. Análisis clásicos y sumamente interesantes, propuestos originalmente por Teresa Gisbert (1980), ilustran esta alternativa de argumentación, según la cual variaciones iconográficas responden a la apropiación local, por parte de comunidades andinas, de motivos o temas importados. Hay tres ejemplos que me parecen especialmente claros en este contexto: la Virgen-Cerro como sincretismo de María con Pachamama; las series de Arcángeles Arcabuceros como sincretismo del motivo de los Arcángeles con el culto a los elementos de la naturaleza; y el motivo del paraíso de los pájaros parlantes, como sincretismo del Jardín del Edén con la representación local del espacio andino. Es interesante notar que en cada uno de estos casos las variaciones iconográficas son seleccionadas y, en último término, asumidas como parte de la tradición iconográfica, según criterios propiamente religiosos en un sentido amplio, entendiendo por esto las comunicaciones que se guían por la observación de una dimensión inmanente de la realidad que cobra sentido a la luz de una dimensión trascendente (Luhmann, 2000). De hecho, del lado del cristianismo organizado se habían tomado decisiones explícitas al respecto en la sesión número 25 del Concilio de Trento, de 1563 (Hecht, 1997; Mujica Pinilla, 2002b).

No es posible revisar aquí de manera detallada cada uno de estos análisis iconográficos, que por lo demás han sido ampliamente difundidos. Pero será útil ver al menos a grandes rasgos la argumentación según la cual el motivo de la Virgen-Cerro responde a un sincretismo entre la persona de María y la divinidad Pachamama, entendida como madre-tierra. Debo ad- 
vertir que esta argumentación ha pasado a formar parte del sentido común en comunicaciones sobre la pintura colonial andina ${ }^{2}$. He encontrado una primera presentación de este argumento en un texto de Teresa Gisbert, de 1980, según el cual, "María engloba en sí muchas cosas, entre ellas la Madre Tierra y por ende el espíritu de las montañas" (1980, p. 21). Me parece que su argumento se puede resumir en seis pasos: 1) Basándose en crónicas de los siglos 16 y 17, Teresa Gisbert asume la existencia de dos cultos pre-hispánicos: el culto al cerro de Potosí, y el culto a Pachamama en Copacabana, en las orillas del lago Titicaca ${ }^{3}$. 2) Gisbert (1980, p. 19) atribuye el diseño del motivo que representa a María en la forma del cerro rico de Potosí, cuya versión más temprana data de $1720^{4}$, a las "elucubraciones alegóricas" de los frailes agustinos Calancha y Ramos, quienes residieron en la región en 1610 y 1619, respectivamente. 3) Tal identificación hubiese sido adoptada por comunidades locales que identificaron el culto al cerro con el culto a María. 4) Tal culto sincrético se difundió desde Potosí a Copacabana, de manera tal que en cada locación María era identificada con un cerro distinto: Pucarini y Sabaya, por ejemplo (Gisbert, 1980, p. 21). 5) Ya que los cerros están compuestos de tierra, la identificación de María con un cerro hubiese permitido que se le identificara con Pachamama, la madre tierra, a pesar de la distinción que las comunidades locales hacían entre Pachamama y los Apus, los espíritus masculinos de las montañas. 6) Comunidades locales habrían adoptado esta identificación entre el culto de la madre tierra con el de María en Copacabana.

${ }^{2}$ Un catálogo publicado por el Museo Nacional de Arte de La Paz, por ejemplo, describe una imagen de la "Virgen Cerro" como sigue: "Esta extraordinaria pintura de la Virgen Cerro es producto de la simbiosis cultural que se da entre mitos indígenas y dogmas de la Iglesia católica. En este caso la Pachamama o Madre Tierra y la Madre de Dios se funden en una sola imagen" ("La Virgen del Cerro", n. d.). El catálogo de la colección de la Casa de Moneda en Potosí presenta otra ilustración de la "Virgen Cerro" del siguiente modo: "The Virgin Mary is portrayed on Potosí Mountain (also called Cerro Rico). The Mountain represents Mother Earth or the Indian Pachamama. It is a sybiosis [sic] of two cultures and two religions around the Holy Trinity, including the sun and the moon" (Bustamante Delgado, 1996, p. 124).

${ }^{3}$ Esta referencia a un culto a Pachamama en Copacabana es tomada por Teresa Gisbert de una crónica de 1621 (Ramos Gavilán, 1988). Véase también el estudio de Verónica Salles-Reese (1997).

${ }^{4}$ Así, Ramón Mujica Pinilla (2003, p. 311) data la imagen de la Virgen Cerro de la Casa de Moneda de Potosí en 1726. Al igual que Teresa Gisbert, este autor alude al texto de Ramos Gavilán como fuente que revela el origen y el sentido de esta metáfora. 


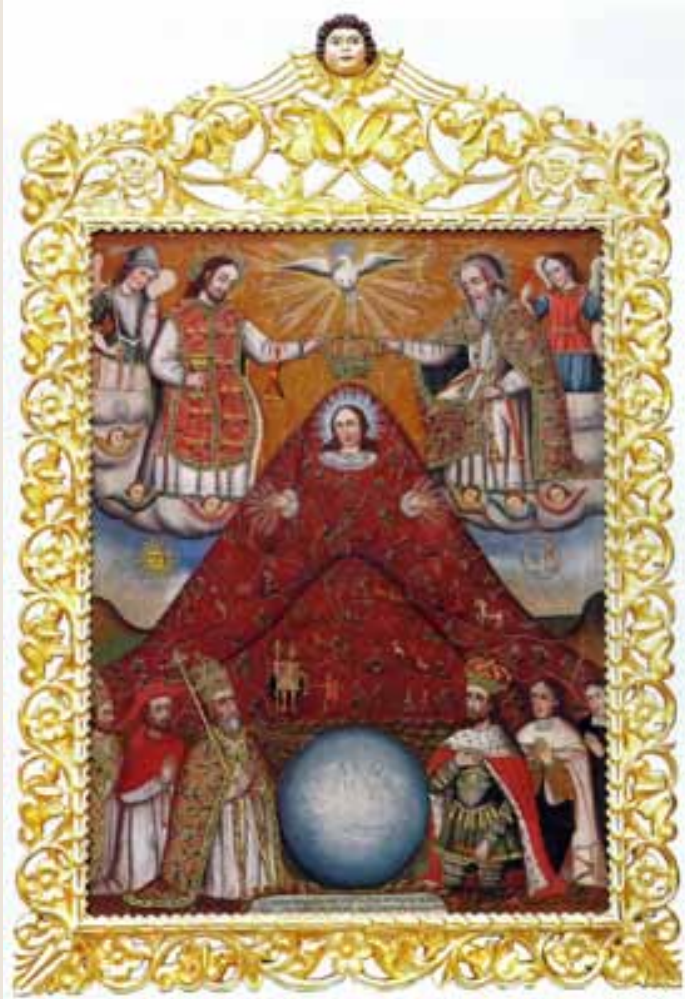

La Virgen del Cerro, anónimo. Museo Nacional de Arte de La Paz.

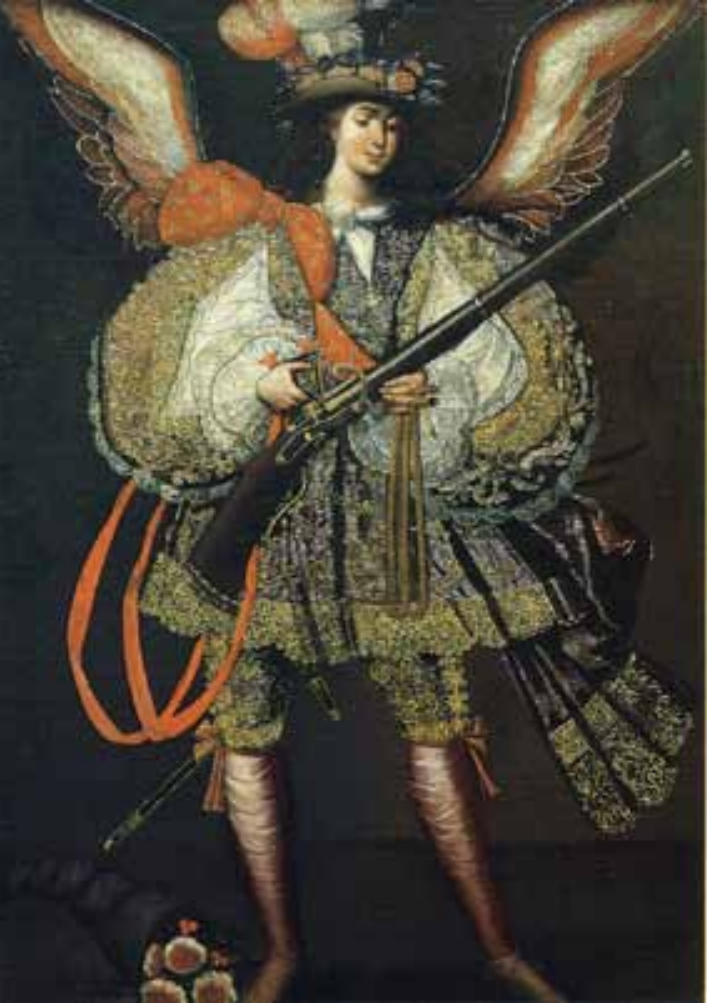

Arcángel Arcabucero.

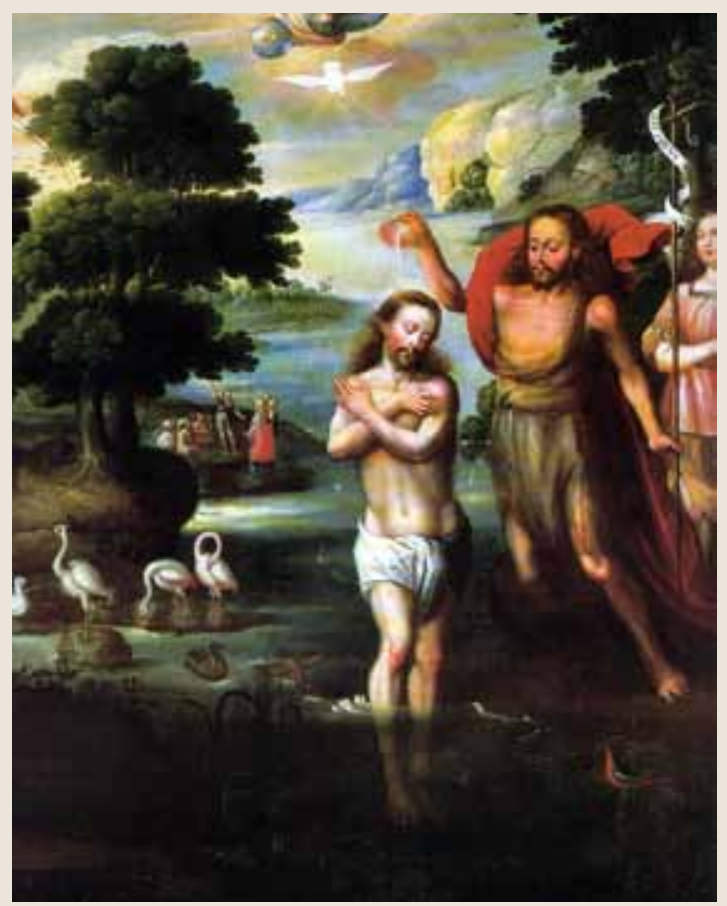

Paraíso de los Pájaros Parlantes 
En otro contexto he señalado lo que me parece que son debilidades importantes de esta alternativa argumental, especialmente en relación con su coherencia interna y su correspondencia con testimonios entregados por otros investigadores de la religiosidad andina (Valenzuela, 2010). Sin embargo, en relación con los objetivos del presente texto, me interesa tan sólo recordar que la fundamental ambigüedad que se constata en el nivel del discurso reflexivo cuando se observa la experiencia de las autoridades eclesiásticas coloniales, se aplica siempre a los autores de estos análisis, a los hermeneutas contemporáneos nuestros que deben realizar siempre una atribución de comprensión que no es comprobable empíricamente. Quizá la desilusión de las autoridades eclesiásticas sea reemplazada por el interés científico contemporáneo por la diversidad cultural, pero el ejercicio interpretativo es similar. Y sin embargo las observaciones convergen en la observación de la función simbólica de estas pinturas (Cruz de Amenábar, 1986; Mujica Pinilla, 1999, 2002a, 2002b, 2003; Picón Salas, 1931), mientras que en el nivel horizontal de los símbolos, es decir de su valor en redes simbólicas, persiste el debate.

A partir de esta constatación me parece que limitarse a establecer la existencia de este conflicto o de esta ambigüedad fundamental que se produce únicamente en la dimensión horizontal de los sistemas simbólicos (dimensión discursiva de la distinción entre símbolos), es sociológicamente más fértil que intentar probar que tal o cual motivo respondió efectivamente a tal o cual tradición local-lo que es siempre una empresa altamente incierta, aunque ciertamente de gran valor para la historia del arte como disciplina.

En relación con la teoría de Pedro Morandé sobre la existencia de un mecanismo de comunicación intercultural, creo que la revisión de esta primera alternativa, que reconoce un proceso de sincretismo iconográfico, sugiere más bien la ausencia de tal mecanismo en el nivel del discurso reflexivo, y alienta a pensar en un mecanismo que operaba en el nivel simbólico o del sacrificio.

\section{III}

Según una segunda tesis que fuera propuesta por Teresa Gisbert y José de Mesa en 1982, que también se ha transformado en lugar común, en objeto de sentido común de la historia del arte en nuestra región (Valenzuela, 2013a), procesos de sincretismo cultural habrían tenido lugar en el nivel estilístico de las pinturas en los Andes centrales, como resultado de conflictos institucionales. 
La pintura cusqueña sería el principal exponente de este singular proceso de evolución sociocultural. Según señala esta teoría, poco antes de 1688 los pintores indios de la ciudad de Cusco se habrían separado del gremio, formando su propia asociación. Esto significaba que el derecho a ejercer el oficio de pintor y a montar una tienda habría dejado de ser monopolio de quienes tenían más poder al interior del gremio. Más específicamente, ya no habría sido un derecho exclusivo de aquellos que rendían exitosamente el examen que hasta entonces había sido impuesto por la facción española del gremio. Dicho examen resguardaba la exigencia de recibir entrenamiento en las principales técnicas de representación pictórica que eran difundidas desde Europa en ese tiempo (principalmente claroscuro, perspectiva central y corrección anatómica). Por eso, la nueva situación en que se encontraban los pintores indios tras independizarse del gremio daba lugar a que se desarrollara una forma de pintura (es decir, un modo de comunicación en un sustrato medial importado) que no asumía tales técnicas. Además, afuera de los talleres agremiados, los pintores indios habrían perdido acceso a las fuentes europeas de innovación artística, por lo que se habrían visto obligados a volver incesantemente a los mismos motivos. Aquí Teresa Gisbert y José de Mesa dan un giro inesperado: ya que los pintores españoles o criollos tampoco tenían acceso a fuentes europeas de innovación artística, Gisbert y de Mesa se ven obligados a buscar otras causas de la tozuda permanencia de los mismos motivos iconográficos en las obras de los autores que ellos indican como indios, lo que caracteriza a la pintura andina en general, y especialmente a la escuela cusqueña.

Este argumento se completa de dos modos. Según una versión débil de este argumento, la nueva forma de pintura (pintura andina) demostraría la libertad técnica recién adquirida, es decir la falta de entrenamiento de los pintores en las técnicas europeas y la baja exposición a sus innovaciones técnicas e iconográficas. Según una versión fuerte de este mismo argumento, esta libertad permitió que los indios imprimieran a sus pinturas rasgos estilísticos que respondían a su "sensibilidad ancestral" (Mesa y Gisbert, 1982, p. 24). Con esto se explicaría, según tal teoría, la predilección por valores decorativos u ornamentales, que se alejaban de los criterios de suficiencia de las fuentes importadas.

Según cualquiera de estas alternativas, del conflicto institucional nace una pintura ornamental, decorativa, ingenua y primitiva, que distorsiona el sentido de la historia del arte occidental por medio de la combinación azarosa de fuentes provenientes de estilos y épocas disímiles, aunque siempre discontinuados, en los más importantes centros del arte mundial. 
Claramente no es posible realizar aquí un análisis detallado de la documentación que ha sido presentada tradicionalmente como sustento de esta narración histórica ni la trayectoria que ésta ha tenido como objeto socialmente construido, hasta llegar a constituirse hoy como lugar común de esta área de investigación. Baste decir que, hasta donde he podido comprobar, tal documentación es deficitaria y que tal narración se apoya más bien en el peso de la tradición (Valenzuela, 2010, 2013a). Para sostener esta narración requerimos más información sobre cuatro aspectos: (1) sobre la situación de los pintores indios en el gremio y sobre su separación de éste, (2) sobre las ordenanzas del gremio y su fecha de fundación, (3) sobre la capacidad del gremio para implementar sus ordenanzas y (4) sobre la situación de estos factores en otras regiones. Con los datos históricos que tenemos hoy en día, no podemos sostener que tal conflicto gremial pudo haber tenido semejantes consecuencias en el arte. Con toda probabilidad tal conflicto ocurrió en un contexto en el cual los pintores indios ya gozaban de grandes niveles de libertad con respecto a las ordenanzas del gremio -como sostenía Felipe Cossío del Pomar ya en la década de 1920 (Cossío del Pomar, 1922, 1928).

Sin embargo, a la luz de la tesis de Pedro Morandé sobre la existencia de un mecanismo de comunicación intercultural que debió influir en las comunicaciones que utilizaban el medio de la pintura durante el período colonial en la región andina, creo que esta segunda alternativa tiene, pese a sus deficiencias, el valor importantísimo de obligarnos a pensar sobre la dificultad que implica para los observadores, y especialmente para los historiadores y críticos de arte en tanto que observadores, distinguir entre la pintura cusqueña -o la andina en general- y la otra pintura: la europea, tildada de academicista sin que existiesen academias. Nos obliga a pensar también, desde la sociología, sobre la necesidad imperiosa que tienen tales observadores de dar cuenta de la genealogía de esta distinción -que es algo que ellos ingresan en el mundo- por referencia a procesos sociales; es decir, en el marco de una historia social del arte.

El hecho sociológicamente relevante es que si estamos frente a un sincretismo en el nivel estilístico de la pintura, es decir si estamos frente a una suerte de intercambio de valores y modalidades culturales entre sociedades que lleva a la cristalización de una forma distinta, quizá propiamente andina -todo lo cual no niego como posibilidad-, tal forma sincrética se señala con tozuda sistematicidad por medio de las categorías de lo decorativo, lo ingenuo, lo primitivo, lo arcaico y lo popular, y con igual sistematicidad se señala como causante de tal carácter ya sea a una cosmología andina, ya 
sea al contexto social e institucional de las pinturas, aun cuando las fuentes documentales sean deficitarias. Como señalaba Niklas Luhmann (1995), la atribución de causalidad corresponde al esquema de observación que utiliza un observador externo.

\section{IV}

Para superar este impasse propongo realizar un análisis de las formas de la observación, en conexión con la sociología de sistemas de Niklas Luhmann. Este análisis se concentra en la deconstrucción de las distinciones que utiliza un observador cuando observa y en el análisis de las estructuras sociales que hacen que tal posición de observación sea posible e, incluso, probable (Luhmann, 1999a). Para ello, utiliza como datos para la realización del análisis sociológico lo que ya hemos aprendido sobre el contexto social de la pintura andina en base a la revisión crítica de la literatura secundaria relativa a las teorías del sincretismo pictórico. Por otra parte, utiliza esta misma literatura secundaria como fuente primaria, en tanto que los esquemas que guían su construcción de información histórica nos dicen mucho sobre la realidad social en la que se sitúa y sobre el carácter de las diferencias en su entorno (en la historia efectiva, en el territorio de la pintura andina) que hacen diferencias en el sistema (en la historia construida y narrada).

Mi tesis es que, en el medio de la pintura, un mecanismo de comunicación entre las culturas andinas y la cultura hispánica operó, hasta bien avanzado el periodo colonial, en el medio de la ornamentación de símbolos hierofánticos en el contexto de un arte primariamente simbólico; es decir, en la aplicación de las operaciones ornamentales propias de la forma del signo al contorno de símbolos hierofánticos, entendiendo por aquellos a símbolos que hacen presente, en su compleja red ornamental inmanente, una realidad trascendente. No se trata ésta de una descripción de un proceso de sincretismo, sino del análisis de un modo de organización de la comunicación por medio de imágenes que, ocupando la posición que Pedro Morandé reservara a una estructura de comunicación intercultural, hizo posible que se dieran sincretismos iconográficos y estilísticos.

Para fundamentar este argumento es necesario distinguir entre el arte que se organiza primariamente en la forma del símbolo y el que lo hace según la forma del signo. Al igual que Niklas Luhmann (2005), sigo en esto a Julia Kristeva (1979). En la línea de Saussure (1983), el concepto de símbolo hace referencia no sólo a un significante, sino a una forma de relación entre el significante y su significado. Tal relación tiene una apariencia ob- 
jetiva, determinada externamente: es decir, es experimentada como estando determinada fuertemente por contextos que sobrepasan los límites de la comunicación que está en curso. En la comunicación, el significado del símbolo se experimenta como habiendo sido dado de antemano, como una forma de comunicación que recibe muy baja determinación de parte del contexto inmediato de la comunicación. Si bien se experimenta una relación necesaria entre el símbolo inmanente y lo trascendente simbolizado, se reconoce a su vez que entre ambos se abre un abismo. De esta manera paradójica, en contextos en donde la realidad es construida primariamente siguiendo la distinción entre una dimensión inmanente y una trascendente, el símbolo trae al mundo inmanente, o hace presente en él, un objeto trascendental, sin identificarse con él. El signo, en tanto, trae consigo un abanico de posibles significados cuya determinación depende de la red de signos de la cual pasa a formar parte. Así, al contrario de lo que ocurre con el símbolo, el significado del signo es fácilmente atribuido a quien lo utiliza. Así, estamos frente a un continuo que responde al nivel de generalización de las distinciones que se trazan en el sentido.

Esta distinción entre símbolo y signo es útil en el ámbito del arte. Siguiendo a Niklas Luhmann (2005), podemos llamar "primariamente simbólico" a aquel arte que apunta a un significado trascendente en su abstrusa red ornamental inmanente. Por su parte la operación característica del signo (su efecto de ser experimentado como una distinción que abre posibilidades que deben ser determinadas en el sentido que co-determina una red de distinciones de la cual pasa a ser elemento) constituye lo que Niklas Luhmann llamara "operación de ornamentación". Cada distinción ingresada por el artista, tenga lugar o no en un mundo de ficción, trae consigo un abanico de posibilidades que deben ser determinadas en el sentido que coestablece una red de distinciones de la cual pasa a ser elemento. Esta operación genera una situación en la cual el ornamento mismo decide entre lo que calza y lo que no calza (lo que tiene y lo que no tiene sentido), creando un espacio imaginario. Este tipo de operación era para Niklas Luhmann la unidad más elemental del proceso artístico, la cual es compartida por todas las formas artísticas. Ella provee un medio en el cual se ha diferenciado un sistema funcional del arte, si bien ha perdurado una gran multiplicidad de formas artísticas en su entorno.

No puedo detenerme aquí a detallar las propiedades del sistema funcional del arte. Pero sí me parece relevante notar que tal sistema parece especializarse en la función de observar la operación propia del sentido en tanto que medio en el cual se reproducen los sistemas sociales y psíquicos 
(Luhmann, 1999b, 2005, 2007; Valenzuela, 2005, 2006, 2014). Esto lo logra por medio de una utilización altamente reflexiva (de segundo orden) de la operación de ornamentación, al demostrar que del trazo de distinciones casuales pueden nacer mundos auto-contenidos. Ello implica que quienes tienen entrenamiento en la observación de tales obras de arte son especialistas en la observación de procesos de emergencia de orden a partir del caos. De ello se desprende que la semántica de la ingenuidad en el arte y el concepto histórico cotidiano de arte ornamental corresponden a la experiencia de aquel que, debido a que tiene entrenamiento en el sistema funcional del arte, encuentra que su modo de observación no es correspondido -es decir, no había sido anticipado- por algún sistema ornamental (Valenzuela, 2013b). Tal sería el caso de las pinturas coloniales de los Andes centrales cuando son leídas por nuestros contemporáneos socializados en las operaciones propias de un sistema funcional del arte.

Ernst Gombrich (1982) ya observaba que en el dominio del arte simbólico es difícil para un observador externo distinguir el límite que separa el ritual del juego: lo que corresponde al símbolo en su forma dada y lo que corresponde a la exploración formal característica de la operación de ornamentación (es decir, al signo en su forma contextualmente delimitada). Mientras que el símbolo, en la forma inmanente que le es dada por la tradición, establece una vía de comunicación con el objeto trascendental que simboliza, el mismo símbolo llama a aprovechar su dimensión inmanente como medio de ornamentación para que esa relación con el objeto simbolizado tome la forma de la reciprocidad. Es decir, la red de distinciones que compone un sistema ornamental se ve gobernada por una distinción central, que distingue entre una dimensión inmanente y una dimensión trascendente, y que está mediada por la forma del símbolo, en torno al cual se trazan nuevas distinciones cuyo sentido es especificado por su contexto ornamental inmediato. Esto implica que la ornamentación se realiza dentro de los límites que fija el símbolo, a la vez que es potenciada por él.

De tal manera, en los contornos de los símbolos nace un medio en el cual la exploración de la estructura fundamental del sentido por medio de la ornamentación se pone al servicio de la comunicación con lo sagrado, al constituir ella un gasto sacrificial que se espera que sea bien recibido por aquello que se simboliza. En otras palabras, la ornamentación permite profundizar una relación de reciprocidad con los objetos simbolizados y con la comunidad entera que aprueba el sacrificio. Piénsese, por ejemplo, en el brocado o brocateado en oro, que se aplicaba a las ropas de los santos en las pinturas cusqueñas. La ornamentación que potencia un arte primariamen- 
te simbólico es fundamentalmente un don -en el sentido de Marcel Mauss (2007) - a través del cual se establece una relación de reciprocidad con la divinidad. Ella está determinada por la institución social del sacrificio, en el sentido de Morandé.

Michael Baxandall (1972) estaba en lo correcto al observar que este medio permite el desarrollo de la ornamentación más allá de los límites impuestos por criterios religiosos. Progresivamente la distinción entre sustrato material inmanente y prototipo trascendente, que está en la base de la forma del arte primariamente simbólico, puede dejar lugar a la distinción entre lo que calza y lo que no calza (what fits/ what doesn't fit) en la red ornamental de distinciones, marcando el paso a un arte que se comprende en la forma del signo. Cuando esto ha ocurrido, el aura de lo sagrado ha sido reemplazado por el aura del arte (Belting, 1990).

Es central para una sociología o una historia social del arte en los Andes centrales reconocer que ese proceso de autonomización del arte estuvo mayormente ausente en la zona andina durante el período colonial. En ello consistió lo que, usando los términos de Pedro Morandé, hemos llamado una estructura de comunicación intercultural en el ámbito de la pintura colonial andina, la cual no se estableció en el nivel del discurso reflexivo, sino en el nivel pre-discursivo del rito y del sacrificio: de la observación eficaz de la dimensión trascendente de la realidad por medio de pinturas. El arte era fiesta y sacrificio en ambos lados de la sociedad colonial, aunque en un contexto de profunda ambigüedad discursiva. Me parece que esto, y no la crisis de las instituciones del mundo del arte -como propone la tesis consensuada de José de Mesa y Teresa Gisbert (1982)-, da cuenta del carácter preeminente de la pintura colonial andina.

\section{REFERENCIAS}

Baxandall, M. (1972). Painting and Experience in Fifteenth-Century Italy: A Primer in the Social History of Pictoral Style. Oxford: Oxford University Press.

Belting, H. (1990). Bild und Kult: eine Geschichte des Bildes vor dem Zeitalter der Kunst. München: C. H. Beck.

Bustamante Delgado, E. (Ed.) (1996). Tesoros del arte virreinal: Casa de Moneda de Potosí. Barcelona: Bustamante Editores.

Cossío del Pomar, F. (1922). Historia crítica de la pintura en el Cuzco. Tesis para optar al grado de Doctor en Filosofía, Historia y Letras. Universidad del Cuzco, Perú.

Cossío del Pomar, F. (1928). Pintura colonial: escuela cuzqueña. Cuzco: Rozas. 
Cruz de Amenábar, I. (1986). Arte y sociedad en Chile 1550-1650. Santiago de Chile: Ediciones Universidad Católica de Chile.

Duviols, P. (1972). La Lutte Contre Les Religions Autochtones Dans Le Pérou Colonial "L'extirpation De L'idolâtrie" entre 1532 et 1660. Lima: Institut Français d'études Andines.

Duviols, P. (1977). La destrucción de las religiones andinas (Conquista y Colonia). (A. Maruenda, Trans.). México: Universidad Nacional Autónoma de México.

Duviols, P. (1986). Cultura andina y represión. Procesos y visitas de idolatrías $y$ hechicerías Cajatambo, siglo XVII. Cusco: Centro de Estudios Regionales Andinos Bartolomé de las Casas.

Duviols, P. (2003). Procesos y visitas de idolatrías: Cajatambo, siglo XVII; con documentos anexos. Lima: IFEA Inst. Francés de Estudios Andinos; Fondo Ed. de la Pontificia Universidad Católica del Perú.

Eliade, M. (1996). Patterns in comparative religion. (R. Sheed, Trans.). University of Nebraska Press.

Esposito, E. (1999). “Two-Sided Forms in Language”. En Baecker, D. (Ed.), Irmscher, M. \& Edwards, L. (Trans.), Problems of Form (pp. 78-98). California: Stanford University Press.

Gisbert, T. (1980). Iconografía y mitos indígenas en el arte. La Paz: Gisbert \& Cía.

Gombrich, E. H. (1982). Ornament und Kunst: Schmucktrieb und Ordnungssinn in der Psychologie des dekorativen Schaffens. (A. Joseph, Trans.). Stuttgart: Klett-Cotta.

Hecht, C. (1997). Katholische Bildertheologie im zeitalter von Gegenreformation und Barock. Studien zu Traktaten von Johannes Molanus, Gabriele Paleotti und anderen Autoren. Berlin: Gebr. Mann Verlag.

Hurtado, M. de la L. (1997). Teatro chileno y modernidad: Identidad y crisis social. Irvine, Calif: Gestos.

Kristeva, J. (1979). Le texte du roman. Approche sémiologique d'une structure discursive transformationnelle. The Hague, Paris, New York: Mouton Publishers.

Lara, J. (1999). “Cristo-Helios americano: La inculturación del culto al sol en el arte y arquitectura de los virreinatos de la Nueva España y del Perú”. Anales del Instituto de Investigaciones Estéticas, 74/75, 29-49.

La Virgen del Cerro (n.d.). Retrieved February 9, 2009, from http://www.mna. org.bo/rb-32.html

Luhmann, N. (1995). Introducción a la teoría de sistemas. (J. Torres N., Ed.). México: Universidad Iberoamericana.

Luhmann, N. (1999a). “CCómo se pueden observar estructuras latentes?”. En Torres N., J. (Trans.), Teoría de los sistemas sociales II (artículos) (pp. 125136). Chile: Universidad de los Lagos, Instituto de Estudios Superiores de Occidente, Universidad Iberoamericana.

Luhmann, N. (1999b). "El arte como mundo (Weltkunst)”. En Teoría de los sis- 
temas sociales II (artículos) (pp. 9-65). Chile: Universidad Iberoamericana, Universidad de Los Lagos, Iteso.

Luhmann, N. (2000). Die Religion der Gesellschaft. Frankfurt am Main: Suhrkamp.

Luhmann, N. (2005). El arte de la sociedad. México: Herder.

Luhmann, N. (2007). La sociedad de la sociedad. México: Herder, Universidad Iberoamericana.

Macera, P. (1977). "Feudalismo colonial americano: El caso de las haciendas peruanas”. In Trabajos de Historia, Vol. III, pp. 139-227. Lima: Instituto Nacional de Cultura.

Mauss, M. (2007). Essai sur le don: Forme et raison de l'échange dans les sociétés archaïques. Paris: Presses universitaires de France.

Mesa, J. de, y Gisbert, T. (1982). Historia de la pintura cuzqueña (2nd ed., Vols. 1-2). Lima: Fundación Augusto N. Wiese, Banco Wiese.

Morandé, P. (1987). Cultura y modernización en América Latina. Ensayo sociológico acerca de la crisis del desarrollismo y de su superación. Madrid: Ediciones Encuentro.

Mujica Pinilla, R. (1999). "El ancla de Santa Rosa de Lima: mística y política en torno a la Patrona de América". En Santa Rosa de Lima y su tiempo (pp. 53-211). Lima: Banco de Crédito del Perú.

Mujica Pinilla, R. (2002a). "Arte e identidad: las raíces culturales del barroco peruano”. En El barroco peruano (Vol. 1, pp. 1-57). Lima: Banco de Crédito.

Mujica Pinilla, R. (2002b). "El arte y los sermones". In El barroco peruano (Vol. 1, pp. 219-313). Lima: Banco de Crédito.

Mujica Pinilla, R. (2003). "Identidades alegóricas: lecturas iconográficas del barroco al neoclásico”. In El barroco peruano (Vol. 2, pp. 258-329). Lima: Banco de Crédito.

Picón Salas, M. (1931, Invierno). "El medievalismo en la pintura colonial”. Sur, I, 162-166.

Ramos Gavilán, A. (1988). Historia del Santuario de Nuestra Señora de Copacabana. Lima, Perú: Ignacio Prado Pastor, Editor.

Rennie, B. S. (1996). Reconstructing Eliade: making sense of religion. Suny Press.

Salles-Reese, V. (1997). From Viracocha to the Virgin of Copacabana: Representations of the Sacred at Lake Titicaca. Austin: University of Texas Press.

Saussure, F. de (1983). Course in General Linguistics (R. Harris, Trans.). London: Duckworth.

Spalding, K. (2002). “La otra cara de la reciprocidad”. En Decoster, J.-J. (Ed.), Incas e indios cristianos: elites indígenas e identidades cristianas en los Andes coloniales (pp. 61-78). Cuzco: Centro de Estudios Regionales Andinos Bartolomé de las Casas.

Valenzuela, F. A. (2005). Nueva narrativa hispanoamericana. Literatura y diferenciación funcional de la Sociedad en América Latina (Magíster en Sociología). Pontificia Universidad Católica de Chile. 
Valenzuela, F. A. (2006). “Arte y entretenimiento en la Nueva Narrativa Hispanoamericana”. Sociología del boom. En Farías, I. y Ossandón, J. (Eds.), Observando sistemas: nuevas apropiaciones y usos de la teoría de Niklas Luhmann (pp. 101-118). Santiago, Chile: Ril.

Valenzuela, F. A. (2010). Painting as a form of communication in colonial central Andes: Variations on the form of ornamental art in early world society. Tesis para optar al grado de Doctor en Sociología. Universität Luzern, Luzern. Disponuble en http://edoc.zhbluzern.ch/unilu/ediss/unilu_diss_ 2012_001_valenzuela_fulltext.pdf

Valenzuela, F. A. (2012). "La vida de los hechos: la codificación de la verdad en la comunicación de la historia social de la pintura colonial en los Andes centrales”. En M. Estrada Saavedra \& R. Millán (Eds.), La teoría de los sistemas de Niklas Luhmann a prueba: Horizontes de aplicación en la investigación social en América Latina (pp. 275-321). México: Universidad Nacional Autónoma de México y Colegio de México.

Valenzuela, F. A. (2013a). "La debilidad institucional del gremio de pintores de Cusco en el período colonial. Un estudio historiográfico”. Colonial Latin American Historical Review-Second Series 1(4), 381-402.

Valenzuela, F. A. (2013b). "La ingenuidad como forma de clasificación social en el arte: un análisis sociológico". Cinta Moebio, 48, 136-146.

Valenzuela, F. A. (2014). "Las formas del arte en la teoría sociológica de Niklas Luhmann”. Contenido. Arte, Cultura y Ciencias Sociales, 4, 9-21. 